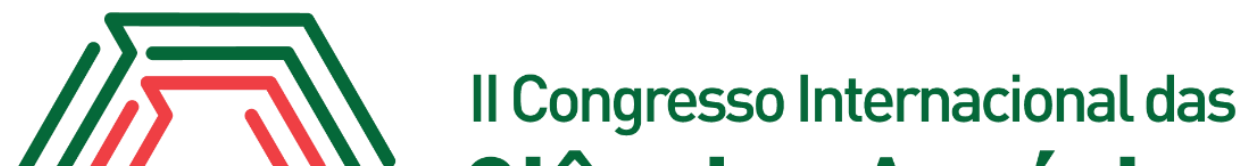 Ciências Agrárias COINTER - PDVAgro 2017
}

\section{UROLITÍASE OBSTRUTIVA EM CAPRINO: RELATO DE CASO}

\author{
Apresentação: Pôster
}

\begin{abstract}
Aluisio de Souza Neto ${ }^{1}$; Desirée Coelho de Mello Seal ${ }^{2}$; Leonardo Lomba Mayer ${ }^{3}$; Fábio Franco Almeida ${ }^{4}$; Tales Gil França ${ }^{5}$.
\end{abstract}

\section{Introdução}

O crescimento da caprinocultura no Brasil e a adoção do sistema de manejo intensivo nas criações em que se utilizam altas concentrações de dietas concentradas, propiciou um aumento das enfermidades de origem nutricional e/ou metabólica nesses animais, como a urolitíase (Antonelli et al, 2012).

A urolítiase e a obstrução do trato urinário são patologias comuns em pequenos ruminantes machos, que promovem a retenção da urina pelo acúmulo de cálculos no trato urinário (Ermilio e Smith, 2011). A urolítiase é uma doença nutricional que ocorre em consequência da precipitação de minerais ou substâncias orgânicas no trato urinário (Riet-Correa et al, 2007), sendo considerado um distúrbio subclínico comum nos ruminantes alimentados com ração composta principalmente de grãos ou quando os animais consomem certos tipos de pastagens com desbalanço Ca e P (Radostits et al, 2002).

Geralmente, nos casos de obstrução uretral pela formação de cálculos, os animais acometidos apresentam sinais clínicos compatíveis com síndrome característica de dor abdominal, esforço para urinar, polaquiúria, urina avermelhada, além de ranger de dentes (Radostits et al, 2002). É uma enfermidade que caracteriza-se por apresentar fácil diagnóstico, entretanto dependendo do grau de acometimento uretral, o tratamento clínico ou cirúrgico pode ser considerado incompatível, deixar sequelas locais ou sistêmicas, ou levar o animal à morte (Guimarães et al, 2012).

\footnotetext{
${ }^{1}$ Estudante Medicina Veterinária, UFERSA, aluisio ifrn@outlook.com

2 Médica Veterinária residente, UFERSA, desiree.seal@hotmail.com

${ }^{3}$ Médico Veterinário residente, UFERSA, leonardomayer@id.uff.br

${ }^{4}$ Médico Veterinário residente, UFERSA, fabio franco77@hotmail.com

${ }^{5}$ Médico Veterinário residente, UFERSA, talesgilfranca@gmail.com
} 
Dessa forma este trabalho tem como objetivo relatar os aspectos clínicos relacionados ao caso de urolítiase obstrutiva em um caprino macho de 3 anos de idade, atendido na Clínica de Grandes Animais do HOVET da UFERSA-Mossoró/RN além de apresentar as condutas terapêuticas que foram instituídas.

\section{Fundamentação Teórica}

O processo patológico caracterizado pela presença de cálculos ou concreções no sistema urinário é denominado urolitíase (Riet-Correa et al, 2008). Os cálculos são formados quando solutos urinários inorgânicos ou orgânicos, por um longo período de tempo são precipitados para fora da solução (Radostits et al, 2002). O fator determinante na formação de cristais que irão compor o cálculo urinário é a elevada concentração de fósforo na urina que é altamente correlacionada de forma positiva com o fósforo sérico. $\mathrm{O}$ pH urinário ácido não impede a formação do urólito se os teores de fósforo urinário estiverem elevados (Antonelli et al, 2012). Ruminantes alimentados com grãos ou seus subprodutos são mais predispostos a urolitíase devido ao fato destes terem níveis de fósforo superiores aos de cálcio, o que leva a proporção de cálcio:fósforo da dieta a níveis de 1:1 ou menores (Riet-correa et al, 2008)

Após a obstrução uretral é possível observar sinais clínicos de dor abdominal aguda, inquietação, dificuldade para andar e marcha rígida. Há tentativas de urinar com rápidos movimentos da cauda e gemidos. Pode ocorrer ruptura da bexiga ou da uretra em casos mais avançados. Em ovinos e caprinos, se a obstrução estiver no processo peniano há sensibilidade da glande e a uretra peniana apresenta-se dilatada, dolorida e hiperêmica. O curso clínico da doença pode ser de 5 a 7 dias, entretanto há relatos que o animal apresentava-se com polaquiúria há 10 dias. O diagnóstico pode ser realizado pelos sinais clínicos, dados epidemiológicos e exames complementares como urina e exame ultrassonográfico. No exame da urina, podem ser observados cristais, hematúria e presença de células inflamatórias (Riet-correa et al, 2007).

Seu tratamento ainda é tido como um grande entrave na produção animal, uma vez que o tratamento cirúrgico é considerado um procedimento de salvamento e que não confere resolução do problema a longo prazo (Radostits et al. 2002). O tratamento utilizado depende do estágio da doença, da natureza e extensão dos cálculos presentes, da função do animal e, frequentemente, das questões financeiras (Dória et al, 2007).

É considerado de caráter emergencial, sendo o objetivo primário ao paciente obstruído o reestabelecimento do fluxo urinário, para isso preconiza-se a utilização de relaxantes musculares 
que atuarão nos músculos retratores penianos com endireitamento da flexura sigmoide facilitando a retirada dos cálculos uretrais (Ferreira, 2013; Riet-correa et al, 2007).

Uma vez estabelecida a obstrução total da uretra a intervenção cirúrgica é necessária. $\mathrm{O}$ tratamento cirúrgico para os casos de urolitíase, pode ser realizado com a utilização de técnicas que incluem a amputação do processo uretral, a uretrostomia e a cistotomia (Dória et al, 2007). Caso o cálculo esteja localizado no processo uretral, a amputação desta região anatômica é um procedimento eficiente (Riet-correa et al, 2007). A uretrostomia também é uma técnica cirúrgica que pode ser empregada (Radostits et al, 2002). Por ser uma doença de alta letalidade a principal forma de se evitar perdas por urolitíase é mediante a profilaxia, assegurando que a relação Ca:P da dieta seja de no mínimo 2:1 (Riet-Correa et al, 2008).

\section{Metodologia}

Foi atendido no hospital veterinário da Universidade Federal Rural do Semiárido-UFERSA, um caprino, macho, 3 anos de idade, pesando $35 \mathrm{~kg}$. Segundo o proprietário, há 3 dias o animal encontrava-se triste, sem urinar e comendo apenas milho. A alimentação fornecida era a base de farelo de milho e trigo, volumoso e água à vontade. No exame clínico, o animal apresentava-se em estação, comportamento apreensivo, tempo de preenchimento capilar 2", frequências cardíaca e respiratória abaixo da normalidade, abdômen abaulado na região dorsal, apresentando dor a palpação. No exame ultrassonográfico abdominal verificou-se a bexiga repleta com presença de urólitos. Além disso, o processo vermiforme apresentava-se necrosado, sendo portanto o diagnóstico clínico sugestivo de obstrução uretral.

O tratamento utilizado neste caso foi a administração de $5 \mathrm{ml}$ de vinagre via sonda uretral, 2 litros de solução fisiológica de cloreto de sódio ( $\mathrm{NaCl}$ 0,9\%), 1,1 ml de Flunixin Meglumine por via intramuscular (IM) e $10 \mathrm{ml}$ de vitamina C em solução fisiológica por via endovenosa. Entretanto, devido ao grau de comprometimento, optou-se pelo procedimento cirúrgico, sendo utilizada a técnica secção do processo vermiforme. Foi instituído ainda, aplicações de $10 \mathrm{ml}$ de vitamina $\mathrm{C}$ por via IM a cada 48 durante 4 dias, e a administração de $100 \mathrm{ml}$ de Cloreto de amônio (1g) diluído em água durante 10 dias.

\section{Resultados e Discussão}

Após o procedimento terapêutico preconizado, animal obteve melhora do quadro clínico com o reestabelecimento do fluxo urinário. A terapia conservativa utilizada, condiz com Riet- 
Correa et al, (2007) que recomendam a administração de acidificantes urinários, anti-inflamatórios e fluidoterapia em casos de urolitíase obstrutiva aguda. Ainda segundo Sousa (2016), deve-se incluir a dissolução de cálculos remanescentes assim que a obstrução é ultrapassada.

A solução salina de $\mathrm{NaCl} 0,9 \%$ e o uso de antiinflamatórios não esteroidais são recomendados por Jones et al, 2012 devido ao grau de desidratação animal e a presença de dor inflamatória no local da lesão. De acordo com Riet-Correa et al, (2008) o mecanismo de ação do cloreto de sódio é o efeito diurético, diluindo as substâncias formadoras de cálculos e aumentando a solubilidade das substâncias urinárias.

Em estudo para avaliar a acidificação urinária em ovinos com tratamentos diferentes, Ferreira (2009) concluiu que o cloreto de amônio e a vitamina $\mathrm{C}$ foram os agentes acidificantes que diminuiram de forma rápida o pH urinário, sendo o tempo de dois dias necessário para acidificação, além de não interferirem em outros parâmetros de urinálise.

A amputação do processo uretral pode ser utilizado como terapia complementar a outros procedimentos. A amputação do processo uretral é o primeiro procedimento cirúrgico a ser efetuado nos pequenos ruminantes com urolitíase sendo por vezes efetuado de forma profilática, sobretudo nos machos reprodutores (Sousa, 2016).

\section{Conclusões}

Os resultados obtidos demonstraram que os procedimentos terapêuticos adotados foram satisfatórios, culminando na alta médica do animal.

A adoção de medidas profiláticas é considerada a melhor forma de se evitar a ocorrência da doença e, consequentemente, perdas econômicas na produção.

\section{Referências}

ANTONELli, A. C.; BARRETO-JÚNIOR, R. A.; MORI, C. S.; SUCUPIRA, M. C. A.; MARCELlO, A. C. S.; ORTOLLANI, E. L. Efeito de diferentes fontes energéticas na predisposição para urolitíase em cabritos. Ciência Animal Brasileira, Goiânia, v.13, n.4, p. 487493, out./dez. 2012

DÓRIA, R. G. S.; CANOLA, P. A.; DIAS, D. P. M.; PEREIRA, R. N.; VALADÃO, C. A. A. Técnicas cirúrgicas para urolitíase obstrutiva em pequenos ruminantes: relato de caso. Arq. Bras. Med. Vet. Zootec., v.59, n.6, p.1425-1432, 2007

ERMILIO, E. M.; SMITH, M. C. Treatment of emergency conditions in sheep and goats. Vet. Clin. Food. Anim. 27 (2011) 33-45.

FERREIRA, D. O. L. Avaliação da acidificação urinária em ovinos com a utilização de três tratamentos. Botucatu, 2010. 108 p. Dissertação (Medicina Veterinária). Faculade de Medicina 
Veterinária e Zootecnia, UNESP, 2010.

FERREIRA, D. O. L. Modelo experimental de urolitíase emo vinos - Estudo clínico, laboratorial e hemogasométrico. Botucatu, 2013. 219 p. Tese (Medicina Veterinária). Faculdade de Medicina Veterinária e Zootecnia, UNESP, 2013.

GUIMARÃES, J. A.; MENDONÇA, C. L.; GUARANÁ, E. L. S.; DANTAS, A. C.; COSTA, N. A.; CÂMARA, A. C. L.; FARIAS, C. C.; AFONSO, J. A. B. Estudo retrospectivo de 66 casos de urolitíase obstrutiva em ovinos. Pesq. Vet. Bras. 32(9):824-830, setembro 2012

RADOSTITS, O. M.; GAY, C. C.; BLOOD, D. C.; HINCHCLIFF, K. W. Clínica veterinária: um tratado de doenças dos bovinos, ovinos, suínos, caprinos e equinos. $9^{\circ}$ ed. Rio de Janeiro. Guanabara Koogan, 2002. 1666 p.

RIET-CORREA, F.; SCHILD, A. L.; LEMOS, R. A. A.; BORGES, J. R. J. Doenças de ruminates e equídeos. $3^{\circ}$ ed. v. 2. Fernovi, 2007. 669 p.

RIET-CORREA, F.; SIMÕES, S. V. D.; VASCONCELOS, J. S. Urolitíase em caprinos e ovinos. Pesq. Vet. Bras. 28(6):319-322, junho 2008.

SOUSA, S. G. F. Urolitíase obstrutiva em pequenos ruminantes: um estudo retrospectivo. Vila Real, 2016. Dissertação (Medicina Veterinária). Universidade de Trás-os-Montes e Alto Douro, 2016. 